\title{
Comparative study on the mortality pattern among elderly people in Japan and Fujian Province, China
}

\author{
Wang Dewen ${ }^{1.2}$, Kurosawa Michiko ${ }^{2}$, Zhou TianShu ${ }^{3}$ and Jiang Qiaoyu ${ }^{4}$
}

Objectives: China and Japan have a common problem in that there will be a rapid increase in the elderly population in the near future. The purpose of this study is to find out the differences which are about the mortality rate between Fujian and Japan. It is expected that the study will contribute to the establishment of the health policy and health promotion of the elderly.

Methods: In the case of China, we compiled and calculated the 1997 death notice data of individuals aged 65 years and over in Fujian Province. The result of mortality rate and age-adjusted mortality was compared with the 1997 Japanese population vital statistics materials. Thus, we obtained the mortality patterns and proportions of individual causes of death among individuals aged 65 years and over.

Results: In both sexes, the mortality rate among elderly people was higher in Fujian than in Japan. In both Fujian and Japan, malignant neoplasms, cerebrovascular diseases (CVD) and heart diseases were the major causes of death, with these three comprising approximately 52$60 \%$ of deaths among elderly individuals. The mortality rates from bronchitis and suicide were remarkably higher in Fujian than in Japan. Upon analyzing site-specific cancer mortality rates in each region, the mortality rate from esophageal cancer was higher in Fujian; the mortality rates from cancers of the lung, colon, breast, and uterus were higher in Japan; and the mortality rates from stomach and liver cancers were similar in Fujian and in Japan.

Conclusions: These differences in mortality rates and proportions of causes of death between Fujian and Japan are thought to be attributable to differences in the available medical services and differences in the levels of risk factors including life-style and environment for each disease. Further study focusing on the death notices data will be necessary.

Key words : Mortality pattern, Elderly people, Fujian, China, Comparative study

\section{Introduction}

In China, the proportion of elderly people will rapidly increase in the near future due to the one-child policy of the Chinese government. The population of Fujian Province, China, in 2002 was

\footnotetext{
Institute of Population Research, Xiamen Uiniversity, China

${ }^{2}$ Department of Epidemiology and Environmental Health, Juntendo University School of Medicine

${ }^{3}$ Fujian Center for Disease Control

${ }^{4}$ Department of Community Health and General Practice, School of Public Health, Fujian Medical University
} 
approximately $34,660,000$, and the proportion of persons aged 65 years and over was $7.6 \%$ (Statistics Bureau of Fujian Province, 2003). However, the importance of improving the health of the elderly population has recently been voiced in China, because the number of elderly people will increase in the near future. The issues faced by elderly people in China are gaining more attention and the number of studies on healthy elderly people in Fujian (Wang D et al., 2001; Wang D et al., 2002) is increasing. Fujian is located in the southeast area of China, and many Chinese who emigrate to foreign countries come from Fujian. After the economic reforms of 1978, the general living standard and health status of the Fujianese have particularly improved among the Chinese. Fujian is also an area that has shown remarkable economic development within China. However, within Fujian, there are large differences in the living conditions between people living in urban areas and those living in villages, and lifestyle-related diseases and infectious diseases are prevalent in Fujian. The mortality rate is an important index that reflects the standard health status of elderly people in a region. The mortality rate in a region is closely related to the environment, life-style, nutrition, and the medical and welfare services that are available in the region. However, there are few published statistics materials of the elderly in Fujian, and there are few detailed comparative studies on the mortality patterns among elderly people between Fujian and a developed country. China and Japan are neighboring countries and have a common problem in that the proportion of elderly people will rapidly increase in the near future. And it is well known that the Japanese is the long life people in the world. In this study, we compared the causes of death and the mortality rate among elderly people living in Fujian Province and Japan, taking into consideration the differences in the health status and lifestyle of people living in Fujian and those living in Japan. The purpose of this study is to find out the differences which are about the mortality rate between Fujian and Japan. It is expected that the study will contribute to the establishment of the health policy and health promotion of the elderly.

\section{Materials and Methods}

The Center for Disease Control in Fujian has randomly selected regions in Fujian by multistage cluster sampling since 1987 for its death notice system. For each death, the cause of death must be certified by a medical doctor in the region, and it must be reported to the health service center in each city or prefecture. In 1997, the selected regions included 2 cities (Fuzhou and Xiamen; the population in the 2 cities was approximately 779,392) and 11 rural prefectures (Changle, Putian, Hui'an, Tong'an, Changtai, Yongding, Shaxiang, Ninhua, Jiangle, Fu'an and Fuqing; the population in the 11 prefectures was approximately $2,477,329$ ), and the total number of people living in these regions was $3,256,721$, comprising approximately $10 \%$ of the population of Fujian Province in 1997. In the 2 cities and 11 rural prefectures, the number of persons aged 65 years and over was 211,533 , which comprised approximately $6.5 \%$ of the population. This proportion of elderly people is similar to the proportion of elderly people in the entire Fujian Province. The causes of death have been classified according to the 9th International Classification of Disease (ICD-9) of the WHO in all of the target regions in Fujian Province. The ICD-9 had been used in Fujian Province until 2003.

We have compiled and calculated the abovementioned data for 1997 to compare the mortality patterns in Fujian and Japan. The result of 
mortality rate and age-adjusted mortality was compared with the 1997 Population Vital Statistics (Statistics and Information Department, Minister's Secretariat, Ministry of Health and Welfare, 1997). Thus, we obtained the mortality patterns and proportions of individual causes of death among individuals aged 65 years and over.

The causes of deaths in Japan have been classified according to the ICD-10. Age-adjusted mortality rates were calculated by the direct method, in which the 2000 total Japan Population (Statistics and Information Department, Minister's Secretariat, Ministry of Health and Welfare, 2000) model was used as the standard population.

\section{Results}

\section{1) Comparison of mortality rates between} Fujian Province and Japan according to age group

Table 1 shows the mortality rates by sex and age and the age-adjusted mortality rate of persons aged 65 years and over in Fujian and in Japan. In Fujian, according to sex, the age-ad- justed mortality rates were $6,293.3$ per 100,000 population among males, and 4,707.0 per 100,000 population among females, which are approximately 1.2-fold and 1.7-fold higher than the corresponding Japanese rates. The mortality rates in Fujian and Japan were both related to age, and the mortality rate was higher in Fujian than in Japan in all age groups. However, the proportion of the number of deaths of individuals aged 65 years and over to the number of deaths in the entire population was lower in Fujian than in Japan. Meanwhile, the mortality rate among men was higher than that among women in both countries.

\section{2) Comparison of the ten leading causes of death between Fujian Province and Japan}

Table 2 shows that the three leading causes of death in Fujian were cerebrovascular disease (CVD), bronchitis, emphysema or asthma and malignant neoplasms. These three causes comprised $57.9 \%$ of the total number of deaths of elderly people. In Japan, the three leading causes

Table 1 Comparison of the Mortality Rates of Elderly People (65 years and over) between Fujian Province and Japan in 1997

\begin{tabular}{lrrrrrr}
\hline \multirow{2}{*}{ Age range (yr) } & \multicolumn{2}{c}{ Total } & \multicolumn{2}{c}{ Men } & \multicolumn{2}{c}{ Women } \\
\cline { 2 - 7 } & Fujian & Japan & Fujian & Japan & Fujian & Japan \\
\hline $65-69$ & 2355.3 & 1328.3 & 3070.1 & 1923.7 & 1697.6 & 796.9 \\
$70-74$ & 3697.2 & 2024.4 & 4923.0 & 2918.3 & 2775.5 & 1337.2 \\
$75-79$ & 5865.9 & 3445.7 & 7619.8 & 5031.1 & 4724.5 & 2494.6 \\
$80-84$ & 9052.8 & 6201.1 & 11290.6 & 8677.8 & 7897.5 & 4834.0 \\
85- & 14129.9 & 13148.8 & 11851.2 & 16768.5 & 15594.1 & 11629.2 \\
\hline Crude Mortality Rate & 4702.0 & 3589.5 & 5435.0 & 4403.2 & 4146.4 & 3014.9 \\
Standardized Mortality Rate ${ }^{2}$ & 5369.6 & 3695.5 & 6293.3 & 5088.5 & 4707.0 & 2843.5 \\
Proportion (\%) & 60.3 & 77.4 & 54.3 & 72.1 & 67.6 & 83.7 \\
\hline 1 Annual rate per 100,000 population & \multicolumn{5}{c}{} \\
2 Mortality rate standardized by the direct method to the age distribution in 5-year age \\
groups of the Japanese population model of elderly people (65 years and over) in 2000. \\
3 Proportion of the number of deaths of individuals aged 65 years and over to the total \\
number of deaths, \%.
\end{tabular}


Table 2 Comparison of the Ten Leading Causes of Death of Elderly People (65 years and over) between Fujian Province and Japan in 1997

\begin{tabular}{|c|c|c|c|c|c|c|}
\hline \multirow{2}{*}{\multicolumn{2}{|c|}{ 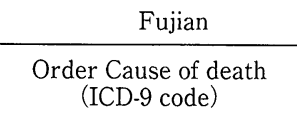 }} & \multicolumn{5}{|c|}{ Japan } \\
\hline & & Crude $^{1}$ & Percent $^{2}$ & $\begin{array}{l}\text { Cause of death } \\
\text { (ICD-10 code) }\end{array}$ & Crude $^{1}$ & Percent ${ }^{2}$ \\
\hline 1 & $\begin{array}{l}\text { Cerebrovascular } \\
\text { diseases }(430-438)\end{array}$ & 1075.3 & 22.87 & $\begin{array}{l}\text { Malignant } \\
\text { neoplasms } \\
\text { (C00-C97) }\end{array}$ & 982.2 & 27.36 \\
\hline 2 & $\begin{array}{l}\text { Bronchitis, } \\
\text { Emphysema } \\
\text { and Asthma } \\
(490-493)\end{array}$ & 932.1 & 19.82 & $\begin{array}{l}\text { Cerebrovascular } \\
\text { diseases } \\
\text { (I60-I69) }\end{array}$ & 609.2 & 16.97 \\
\hline 3 & $\begin{array}{l}\text { Malignant neoplasms } \\
(140-208)\end{array}$ & 717.3 & 15.20 & $\begin{array}{l}\text { Heart diseases } \\
\text { (I01-02.0, I05-I09, } \\
\text { I20-I25, I27, I30-52) }\end{array}$ & 597.8 & 16.65 \\
\hline 4 & $\begin{array}{l}\text { Heart diseases } \\
(393-398,410-416, \\
420-429)\end{array}$ & 698.3 & 14.85 & $\begin{array}{l}\text { Pneumonia } \\
\text { (J12-J18) }\end{array}$ & 377.3 & 10.51 \\
\hline 5 & $\begin{array}{l}\text { Hypertensive diseases } \\
(401-404)\end{array}$ & 166.4 & 3.54 & $\begin{array}{l}\text { Accidents } \\
\text { (V01-X59) }\end{array}$ & 109.2 & 3.04 \\
\hline 6 & $\begin{array}{l}\text { Accidents } \\
\text { (E800-949, } \\
\text { E970-999) }\end{array}$ & 107.8 & 2.29 & $\begin{array}{l}\text { Senility } \\
\text { (R54) }\end{array}$ & 108.8 & 3.03 \\
\hline 7 & $\begin{array}{l}\text { Suicide } \\
\text { (E950-E959) }\end{array}$ & 61.9 & 1.32 & $\begin{array}{l}\text { Nephritis } \\
\text { (N00-N19) }\end{array}$ & 88.2 & 2.46 \\
\hline 8 & $\begin{array}{l}\text { Tuberculosis } \\
\text { (011) }\end{array}$ & 52.5 & 1.12 & $\begin{array}{l}\text { Bronchitis, } \\
\text { Emphysema } \\
\text { and Asthma } \\
\text { (J41-J46) }\end{array}$ & 81.8 & 2.28 \\
\hline 9 & $\begin{array}{l}\text { Mental Disorders } \\
(290-319)\end{array}$ & 52.2 & 1.11 & $\begin{array}{l}\text { Diabetes Mellitus } \\
\text { (E10-E14) }\end{array}$ & 48.3 & 1.35 \\
\hline 10 & $\begin{array}{l}\text { Nephritis } \\
(580-589)\end{array}$ & 52.0 & 1.11 & $\begin{array}{l}\text { Chronic liver } \\
\text { diseases and } \\
\text { Cirrhosis } \\
(\text { K70-K76) }\end{array}$ & 42.9 & 1.20 \\
\hline
\end{tabular}

${ }^{1}$ Crude mortality rate, annual rate per 100,000 population

${ }^{2}$ Percentage to the total number of deaths of individuals aged 65 years and over, $\%$

of death were malignant neoplasms, CVD and heart diseases. These three causes of death comprised $61.0 \%$ of the total number of deaths.

Regarding the various causes of death, in Fujian, the mortality rate from CVD was the highest, being higher than the mortality rate from malignant neoplasms or heart diseases. The mortality rate from bronchitis, emphysema or asthma was high, comprising $19.9 \%$ of the total number of deaths of elderly people. However, in Japan, the mortality rate from malignant neoplasms was the highest, being higher than the mortality rate from CVD or heart diseases, and there was no clear difference between the mortality rates from CVD or heart diseases. In addition, the rank of tuberculosis and suicide as causes of death were much higher in Fujian than in Japan. The rank of senility as a cause of death was sixth in Japan, while senility was not among the ten leading causes of death in Fujian.

Tables 3 and 4 show the rank of the causes of death among males and females in Fujian and Japan, respectively. In Fujian, although the first and second leading causes of death among men and those among women were the same, the third leading cause of death was malignant neo- 
Table 3 Comparison of the Ten Leading Causes of Death of Elderly Men (65 years and over) between Fujian Province and Japan in 1997

\begin{tabular}{|c|c|c|c|c|c|c|}
\hline & Fujian & & & Japan & & \\
\hline Order & $\begin{array}{l}\text { Cause of death } \\
\quad \text { (ICD-9) }\end{array}$ & Crude $^{1}$ & Percent ${ }^{2}$ & $\begin{array}{l}\text { Cause of death } \\
\quad \text { (ICD-10) }\end{array}$ & Crude $^{1}$ & Percent $^{2}$ \\
\hline 1 & $\begin{array}{l}\text { Cerebrovascular } \\
\text { diseases }\end{array}$ & 1245.3 & 22.91 & Malignant neoplasms & 1429.7 & 32.47 \\
\hline 2 & $\begin{array}{l}\text { Bronchitis, } \\
\text { Emphysema } \\
\text { and Asthma }\end{array}$ & 1091.4 & 20.08 & $\begin{array}{l}\text { Cerebrovascular } \\
\text { diseases }\end{array}$ & 655.7 & 14.89 \\
\hline 3 & $\begin{array}{l}\text { Malignant } \\
\text { neoplasms }\end{array}$ & 1052.3 & 19.36 & Heart diseases & 649.4 & 14.75 \\
\hline 4 & Heart diseases & 706.3 & 12.99 & Pneumonia & 479.3 & 10.89 \\
\hline 5 & $\begin{array}{l}\text { Hypertensive } \\
\text { diseases }\end{array}$ & 195.2 & 3.59 & Accidents & 144.8 & 3.29 \\
\hline 6 & Accidents & 108.9 & 2.00 & $\begin{array}{l}\text { Bronchitis, Emphysema } \\
\text { and Asthma }\end{array}$ & 131.6 & 2.99 \\
\hline 7 & Tuberculosis & 85.2 & 1.57 & Nephritis & 92.8 & 2.11 \\
\hline 8 & $\begin{array}{l}\text { Chronic liver } \\
\text { diseases and } \\
\text { Cirrhosis }(571)\end{array}$ & 66.2 & 1.22 & Senility & 78.3 & 1.78 \\
\hline 9 & Suicide & 65.4 & 1.20 & $\begin{array}{l}\text { Chronic liver diseases } \\
\text { and Cirrhosis }\end{array}$ & 56.8 & 1.29 \\
\hline 10 & Nephritis & 62.5 & 1.15 & Diabetes Mellitus & 52.4 & 1.19 \\
\hline
\end{tabular}

${ }^{1}$ Crude mortality rate, annual rate per 100,000 population

2 Percentage to the total number of deaths of individuals aged 65 years and over, $\%$

Table 4 Comparison of the Ten Leading Causes of Death of Elderly Women (65 years and over) between Fujian Province and Japan in 1997

\begin{tabular}{|c|c|c|c|c|c|c|}
\hline & Fujian & & & Japan & & \\
\hline Order & Cause of death & Crude $^{1}$ & Percent $^{2}$ & Cause of death & Crude $^{1}$ & Percent $^{2}$ \\
\hline 1 & $\begin{array}{l}\text { Cerebrovascular } \\
\text { diseases }\end{array}$ & 946.6 & 22.83 & $\begin{array}{l}\text { Malignant } \\
\text { neoplasms }\end{array}$ & 666.2 & 22.10 \\
\hline 2 & $\begin{array}{l}\text { Bronchitis, } \\
\text { Emphysema } \\
\text { and Asthma }\end{array}$ & 811.4 & 19.57 & $\begin{array}{l}\text { Cerebrovascular } \\
\text { diseases }\end{array}$ & 576.5 & 19.12 \\
\hline 3 & Heart diseases & 550.7 & 16.70 & Heart diseases & 561.3 & 18.62 \\
\hline 4 & $\begin{array}{l}\text { Malignant } \\
\text { neoplasms }\end{array}$ & 463.4 & 11.18 & Pneumonia & 305.3 & 10.13 \\
\hline 5 & $\begin{array}{l}\text { Hypertensive } \\
\text { diseases }\end{array}$ & 144.6 & 3.49 & Senility & 130.4 & 4.33 \\
\hline 6 & Accidents & 101.9 & 2.46 & Nephritis & 84.9 & 2.82 \\
\hline 7 & Suicide & 59.3 & 1.43 & Accidents & 84.0 & 2.79 \\
\hline 8 & $\begin{array}{l}\text { Diabetes Mellitus } \\
(250)\end{array}$ & 56.5 & 1.36 & $\begin{array}{l}\text { Bronchitis, } \\
\text { Emphysema and } \\
\text { Asthma }\end{array}$ & 46.7 & 1.55 \\
\hline 9 & Mental Disorders & 65.2 & 1.36 & Diabetes Mellitus & 45.3 & 1.50 \\
\hline 10 & $\begin{array}{l}\text { Pneumonia } \\
(480-486)\end{array}$ & 49.0 & 1.18 & $\begin{array}{l}\text { Hypertensive } \\
\text { diseases } \\
\text { (I10-15) }\end{array}$ & 36.4 & 1.21 \\
\hline
\end{tabular}

${ }^{1}$ Crude mortality rate, annual rate per 100,000 population

2 Percentage to the total number of deaths of individuals aged 65 years and over, $\%$ 
plasms among men and heart diseases among women, and the fourth leading cause of death was heart diseases among men and malignant neoplasms among women. In Japan, the first to fourth leading causes of death among men and those among women were the same. One similarity between Fujian and Japan was that the mortality rate from malignant neoplasms among men was twice as high as that among women. Another similarity between Fujian and Japan was that chronic liver disease or cirrhosis was among the ten leading causes of death among men, but not among women.

\section{3) Comparison of the age-adjusted mortali- ty rates from the major causes of death between Fujian Province and Japan}

Table 5 shows the age-adjusted mortality rates from selected causes of death of elderly people (65 years and over) in Fujian Province and Japan in 1997. The age-adjusted mortality rate were calculated by the direct method to the age distribution in 5-year age groups of the
Japanese population model of elderly people (65 years and over) in 2000. The age-adjusted mortality rates from CVD, bronchitis, emphysema or asthma, heart diseases, hypertensive diseases and suicide both among men and among women were higher in Fujian than in Japan. The age-adjusted mortality rate from CVD was 1.9 -fold (men) and 2.0-fold (women) higher in Fujian than in Japan; that from bronchitis, emphysema or asthma was 8.4-fold (men) and 21.1-fold (women) higher in Fujian than in Japan; that from heart diseases was 1.2-fold (men) and 1.5-fold (women) higher in Fujian than in Japan; that from hypertensive diseases was 6.7-fold (men) and 4.7-fold (women) higher in Fujian than in Japan; and that from suicide was 1.6-fold (men) and 2.5-fold (women) higher in Fujian than in Japan. On the other hand, the age-adjusted mortality rate from pneumonia was 8.4-fold (men) and 4.9-fold (women) higher in Japan than in Fujian; and that from malignant neoplasms was 1.5-fold (men) and 1.4-fold (women) higher in Japan than in Fujian.

Table 5 Comparison of age-adjusted Mortality Rates from Selected Causes of Death of Elderly People (65 years and over) between Fujian Province and Japan in 1997

\begin{tabular}{lrrrr}
\hline & \multicolumn{2}{c}{ Men } & \multicolumn{2}{c}{ Women } \\
\hline & Fujian & Japan & Fujian & Japan \\
\hline Malignant neoplasms & 1021.6 & 1537.6 & 462.9 & 645.5 \\
Cerebrovascular diseases & 1450.2 & 783.7 & 1050.5 & 538.6 \\
Heart diseases & 947.7 & 765.7 & 806.4 & 525.5 \\
Hypertensive diseases & 230.7 & 34.4 & 158.7 & 33.6 \\
Pneumonia & 71.7 & 605.1 & 57.2 & 282.6 \\
Bronchitis, Emphysema and Asthma & 1333.5 & 158.2 & 924.9 & 43.9 \\
Chronic liver diseases and Cirrhosis & 66.4 & 58.9 & 39.5 & 32.1 \\
Diabetes Mellitus & 48.5 & 58.1 & 58.1 & 43.2 \\
Accidents & 125.0 & 164.1 & 110.0 & 80.0 \\
Suicide & 68.6 & 43.0 & 61.6 & 24.5 \\
\hline
\end{tabular}

Mortality rate was standardized by the direct method to the age distribution in 5 year age groups of the Japanese population model of elderly people (65 years and over) in 2000. 
4) Comparison of age-adjusted mortality rates from malignant neoplasms at selected sites between Fujian Province and Japan

Table 6 shows the age-adjusted mortality rates from malignant neoplasms at selected sites in men and women in Fujian and in Japan. The age-adjusted mortality rates from stomach, esophageal, lung, and liver cancers were the four highest among men in Fujian, and those from lung, stomach, liver, and colon cancers were the four highest among men in Japan. The age-adjusted mortality rates from stomach, esophageal and liver cancers were the three highest values among women in Fujian, and those from stomach, colon and lung cancers had the three highest among women in Japan. The age-adjusted mortality rate from esophageal cancer among men was about 4.0-fold higher in Fujian than in
Japan. On the other hand, the age-adjusted mortality rates from intestinal cancer, lung cancer, stomach cancer, liver cancer and urinary bladder cancer among men were much higher in Japan than in Fujian. Among men, the age-adjusted mortality rate from intestinal cancer was 2.7-fold higher in Japan than in Fujian; that from lung cancer was 2.1-fold higher; that from leukemia was 4.2-fold higher; and that from urinary bladder cancer was 2.3-fold higher. Among women, the age-adjusted mortality rate from esophageal cancer was 10.3-fold higher in Fujian than in Japan, and those from stomach cancer and liver cancer were slightly higher in Fujian than in Japan. However, the age-adjusted mortality rates from cancer of lung, uterine and breast were approximately 2.0 -fold higher among Japanese women than among women in Fujian, and that from urinary bladder cancer was 6.3-

Table 6 Comparison of the age-adjusted Mortality Rate from Malignant Neoplasms at Various Sites in Elderly People (65 years and over) between Fujian Province and Japan in 1997

\begin{tabular}{|c|c|c|c|c|}
\hline \multirow{2}{*}{$\begin{array}{l}\text { Cause of death } \\
\text { (ICD-9, ICD-10 code) }\end{array}$} & \multicolumn{2}{|c|}{ Men } & \multicolumn{2}{|c|}{ Women } \\
\hline & Fujian & Japan & Fujian & Japan \\
\hline $\begin{array}{l}\text { Malignant Neoplasm of Stomach } \\
\text { (ICD-9: 151, 230.2 ICD-10: C16) }\end{array}$ & 297.7 & 302.2 & 111.8 & 106.7 \\
\hline $\begin{array}{l}\text { Malignant Neoplasm of Esophagus } \\
\text { (ICD-9:150, 230.1 ICD-10: C15) }\end{array}$ & 218.6 & 54.1 & 95.6 & 9.3 \\
\hline $\begin{array}{l}\text { Malignant Neoplasm of Liver Specified } \\
\text { as Primary (ICD-9: } 155,230.8 \text { ICD-10: C22) }\end{array}$ & 167.6 & 169.5 & 65.8 & 64.2 \\
\hline $\begin{array}{l}\text { Malignant Neoplasm of Trachea, Bronchus } \\
\text { and Lung (ICD-9; 162, 231.1-231.2. ICD-10: C33-34) }\end{array}$ & 170.7 & 363.9 & 53.8 & 86.0 \\
\hline $\begin{array}{l}\text { Malignant Neoplasms of Colon, Rectum, } \\
\text { Rectosigmoid Junction and Anus } \\
\text { (ICD-9: 153-154, 230.3-230.6. ICD-10: C18-C21) }\end{array}$ & 56.5 & 153.5 & 45.3 & 90.9 \\
\hline $\begin{array}{l}\text { Malignant Neoplasm of Uterus and Cervix } \\
\text { (ICD-9: } 180,182.233 .1, \text { ICD-10: C53) }\end{array}$ & - & - & 12.2 & 25.0 \\
\hline $\begin{array}{l}\text { Leukemia } \\
\text { (ICD-9 : 204-208, ICD-10 : C91-C95) }\end{array}$ & 6.1 & 25.3 & 4.9 & 12.5 \\
\hline $\begin{array}{l}\text { Malignant Neoplasm of Female Breast } \\
\text { (ICD-9:174, 233.0, ICD-10: C50) }\end{array}$ & - & - & 12.3 & 25.5 \\
\hline $\begin{array}{l}\text { Malignant Neoplasm of Urinary Bladder } \\
\text { (ICD-9: 188, 233.7, ICD-10: C67) }\end{array}$ & 14.1 & 32.3 & 1.5 & 9.5 \\
\hline
\end{tabular}

Mortality rate standardized by the direct method to the age distribution in 5-year age groups of the Japanese population model of elderly people (65 years and over) in 2000. 
fold higher among Japanese women than among women in Fujian. Comparing men and women, the age-adjusted mortality rates from malignant neoplasms at various sites among men were much higher than those among women in both countries.

\section{Discussion}

\section{1) Mortality rate among elderly people and differences in environment, lifestyle, and medical services between Fujian Province and Japan}

In this study, it was clarified that the mortality rate among senior citizens in Fujian was higher than that in Japan. The life expectancy of Japanese people is known to be high. Presently, persons aged 65 years and over comprise approximately $18 \%$ of the entire population of Japan (Health and Welfare Statistics Association 2001). Many studies on senior citizens have been conducted in Japan. On the other hand, epidemiological studies on senior citizens in Fujian have begun to be conducted only several years ago. This study is the first attempt to analyze the mortality pattern of senior citizens in Fujian by using the data of CDC.

(1) Differences in Environment between the Two Regions.

Numerous epidemiological studies addressed the effects of air pollution, water pollution, as well as lifestyle/household factors on the morbidity or mortality in human. The rapid industrial development that began in the 1950's created environmental problems in Japan. The Japanese national government and local environmental authorities have exerted much effort to control pollution as well as to provide solutions to health problems since 1970s (Maeda K et al, 1996; Matsuo $\mathrm{T}, 2003)$. Likewise, after economic reform started in China in the late 1970s, environmental prob- lem was intensified by industrialization, urbanization and economic development. Some Chinese researchers have measured levels of various pollutants in both urban and rural region areas (Fu L et al, 2001; Junfeng Zhang et al, 2002). According to the data (WHO 1995), in urban areas more than $50 \%$ of the households use coal as the major fuel. And the percentage of that in rural areas accounts for $21.9 \%$. Maybe the percentage is low due to higher cost of the coal use than other kinds of fuels such as wood (36.4\%), crop residues (37.8\%). Hence, one may say that the kind of fuel used is an important source of pollution. Air pollution, such as fine particulate matter, sulphur dioxide, nitrogen oxide, etc. which came from the exhaust of vehicles, industrial process, coal burning and so on, is one of the most visible environmental problems in China, especially in urban areas (Chaoyang Peng et al, 2002). Indoor air pollution also plays an important role in promoting air pollution. Some Chinese medical experts claim that indoor air pollution comprising cooking fuel use, smoking and passive smoking, exposure to benzo etc. is a more serious threat than out-door air pollution in China (Marilyn Beach, 1999). Consequently, it is believed that China should lose no time to tackle the health damages related to environmental pollution. The Chinese leadership is aware that something needs to be done about the environmental problems in recent years. Nevertheless, there still remains the problem as to how to resolve the conflicts of interest among the agencies of enforcement that may result from the economic and bureaucratic balances of power.

(2) The Effects of Changes in Lifestyle and Dietary Patterns on health

The changes in lifestyle and dietary patterns are increasingly significant causes of the preva- 
lence of chronic diseases. It is said that Japanese diet is the most well-balanced diet in point of nutrition in the world. However, lifestyle and dietary patterns have changed in Japan since World War 「(Kato I et al, 1987), leading to the change in the composition of diseases. Many of the diseases suffered by elderly persons in the world are the result of dietary factors, some of which have been operating since infancy. Meanwhile, reduced food intake and a lack of variety in the foods the elderly people eat also results in micronutrient deficiencies. The result is that chronic diseases often occur, thus increasing the economic burden of all families and the whole society. In China, both malnutrition and over-nutrition exist (Popkin BM, et al., 1993). In the poverty areas, malnutrition (including energy-protein malnutrition; micronutrient deficiencies) makes people vulnerable to disease and premature death. On the other hand, rapid change in diets and lifestyles resulting from industrialization, urbanization, economic development and market globalization makes people suffer from the chronic diseases in the developed cities in China just as what have happened in developed countries. In order to achieve the goal of healthy ageing and active ageing, Japan has developed a administrable system focused on nutrition and food security since 1960s. (Health and Welfare Statistics Association, 2001) In China, the country needs to pay more attention to the promotion of nutrition, including dietary patterns and food security.

(3) Different Levels of Medical Services

There are many differences in the medical establishments and human resources for health between China and Japan. According to the report of the Second National Health Services Survey in China in 1998, the number of hospitals, beds, physicians and nurses per 100,000 population in
1997 in Fujian were 4.0, 251, 126 and 83, respectively (Editorial Committee of Fujian Yearbook, 1998; Ministry of Health People's Republic of China, 1998). In contrast, the corresponding figures in 1997 or 1998 in Japan were 7.5, 1,316.3, 196.6 and 779.4, respectively (Health and Welfare Statistics Association, 1999; Health and Welfare Statistics Association, 2000). In 1999, there were 1,032 hospitals and 114,418 beds for senior citizens in Japan (Health and Welfare Statistics Association 2001). In contrast, there was only one hospital for senior citizens in Fujian in 1990s. It seems that the poor accessibility of senior citizens in China to medical services has influenced their health. In Japan, there is a law ensuring that health care services are available to senior citizens (Maedo K, et al., 2000; Shimokata H, et al., 2000). The distribution of the expenses of medical treatment in China and Japan greatly differ. Many senior citizens in China suffer economic hardship due to the high medical costs (Liu Y, et al. 2003; Tu F, et al. 2002) Medical services are more accessible to elderly people in Japan than to those in Fujian. Altogether less pollution, healthier lifestyle and more accessible medical services have reduced the mortality rate among the elderly in Japan.

\section{2) Comparability of the ICD-9 and ICD-10}

In this study, we used the 1997 death notice data of Fujian, in which the causes of death were classified according to the ICD-9, and the 1997 Japanese population Vital Statistics materials, in which the causes of death were classified according to the ICD-10. In Fujian, the ICD-9 had been used until 2003. When comparing the causes of death in Fujian and Japan, the ICD-9 classification in Fujian had to be compared with Japan's ICD-10 classification.

A table that compares the ICD-9 and ICD-10 
classifications of death data in Japan in 1994 is shown on a homepage (http://www.mhlw.go. jp/toukei/sippei/icd.html) of the Statistics and Information Department, Minister's Secretariat, Ministry of Health, Labour and Welfare, Japan. As to the number of deaths from CVD, according to the table, the percentage in the ICD-10 of $13.0 \%$ is higher than that in the ICD-9. The number of cases of CVD as the primary cause of death was higher in the ICD-10 because of a change in the selection criteria; the combination of pneumonia and bronchitis led to an increase in the number of deaths from CVD in the ICD-10. As for the number of deaths from malignant neoplasms, according to the table, the percentage in the ICD-10 of $2.8 \%$ was higher than that in the ICD-9. The number of cases of malignant neoplasm as the primary cause of death was higher in the ICD-10 because of a change in the selection criteria; the combination of infectious diseases, pneumonia and cirrhosis led to an increase in the number of deaths from malignant neoplasms in the ICD-10. As for the proportion of deaths from bronchitis, emphysema and asthma, according to the table, the percentage in the ICD-10 was $1-2 \%$ higher than that in the ICD-9. As for the mortality rate from nephritis in Japan, the percentage in the ICD-10 classification was lower than that in the ICD-9 classification by about $5 \%$. When the mortality data of Fujian and Japan were compared, close attention was paid to these differences between the ICD-9 and ICD10 classifications.

\section{3) Comparison of the major causes of death}

Lifestyle-related diseases such as CVD, malignant neoplasms, and heart disease were the main causes of death of elderly people in Fujian as well as in Japan. The proportion of deaths due to malignant neoplasms, CVD and heart disease to the total number of deaths was $61 \%$ in Japan and $53 \%$ in Fujian. Even when the influence by the cause-of-death classification was considered, the proportion in Japan was still higher than that in Fujian.

The mortality rates from bronchitis, emphysema and asthma and other infectious diseases were higher in Fujian. Infectious disease is still a major life-threatening disease that affects elderly people in Fujian. This is very different from the situation in Japan. In a word, the proportion of deaths from lifestyle-related diseases was higher in Japan, while the proportion of deaths from lifestyle-related diseases in Fujian was lower relatively but its infectious disease was higher compared to Japan. "Senility" ranked as the sixth most common cause of death in Japan, while senility was not among the top ten leading causes of death in Fujian. It seems that the differences in the leading causes of death in the elderly population between the two regions reflect the differences in environmental conditions, socio-economic status, lifestyle medical services etc. between developing and developed countries. The previous analysis indicates that non-communicable disease is on the way of globalization and continuing to be a serious menace to mankind, particularly to the elderly people.

\section{4) CVD as a cause of death}

In Fujian, the leading cause of death among elderly people of both sexes was CVD, and the mortality rates of CVD and hypertensive disease were much higher in Fujian than in Japan. CVD is the first or second leading cause of death in nearly all areas of China (Gu D, et al., 2003). It is believed that CVD, especially cerebral hemorrhage, is related to hypertensive disease (He J, et al., 1995). In Japan, CVD was the leading cause of death in 1965 (Ueshima H. 2001). However, the 
mortality rate from CVD in Japan decreased after a public campaign advocating a low-salt diet, abstinence from smoking, control of hypertensive diseases, etc. (Ueshima H. 2001). The incidence of stroke differs in Japan and Fujian, and this may be partly due to differences in diet, alcohol and cigarette consumption, or to the difference in the prevalence of hypertensive disease.

According to the national investigation conducted by the Ministry of Health in 1991 (http:// zgjbkz.51.net), the standardized hypertension rate among the people aged 15 and over is $11.3 \%$. In urban areas only $36.3 \%$ of the persons are aware of the hypertension, and in rural areas the rate is $13.7 \%$. Among the people with hypertension, only $17.4 \%$ are treated in urban areas, and the rate in rural areas is $5.4 \%$. It is estimated that the control rate of hypertension is much lower than the rate treated. So the public health educational program to reduce the incidence of hypertension and stroke in China should be enhanced, and should be directed particularly towards elderly people in China because they suffer more frequently from hypertension, CVD and coronary heart disease.

\section{5) Bronchitis as the cause of death}

The mortality rate from chronic bronchitis was obviously higher in Fujian than in Japan. Since the diagnostic criteria of bronchitis are not clear, patients with pneumonia might have been diagnosed as having bronchitis. Moreover, the symptoms of pneumonia in elderly people are not always typical; therefore, some cases that were actually pneumonia may have been diagnosed as another syndrome. However, even if these points are considered, the mortality rate from bronchitis was extremely high among elderly people in Fujian. Even when the mortality rates from bronchitis disease (bronchitis, emphy- sema or asthma) and pneumonia in Japan were added, the value was still lower than the mortality rate from bronchitis disease (bronchitis, emphysema or asthma) in Fujian. In Japan, smoking as a major risk factor to health has received much public attention since 1970s. Since then, Japan has exerted every effort to reduce the death rate caused by smoking, which, according to many studies, is the main cause of respiratory tract carcinoma and other related disease (Sobue $\mathrm{T}, 2001)$. In China, many studies also have described the association between respiratory tract disease and air pollution or cigarette smoking (Xu $\mathrm{Z}$ et al, 2000; Lam TH et al., 1991). In Fujian, coal and wood are the main sources of heat for home heating and cooking. Moreover, the smoking rate among men in Fujian is very high. According to a data in The Tobacco Atlas (Judith Mackay et al, 2002), the percentage of male adult smoking is $66.9 \%$, and the female $4.2 \%$ in China. The percentage of youth exposed to passive smoking at home is $53.0 \%$. The high smoking rate has led to the expansion of the tobacco industry. Cigarette sales in China have continued to increase since 1970 s, it especially gained an higher growth rate since 1980s (Chinese Academy of Preventive Medicine 1997). These are thought to be the reasons for the high mortality rate from chronic bronchitis in Fujian. Additionally, the high mortality rate from bronchitis, emphysema or asthma must be related to the poor medical services that are available to people living in rural areas of Fujian.

\section{6) Suicide as a cause of death}

Suicide is one of the leading causes of injury death in China (Li G, et al., 1986). As for the reasons for suicide by elderly people in China, poverty, low education, lack of health insurance and pensions, and the decrease in traditional 
family relationships may contribute to the extremely high suicide rate. In Fujian, injury (including suicide) research is only now starting to be conducted. The elderly populations of Fujian were all born before the birth of New China in 1949, their educational level is low, and the proportion of illiterate persons is above $50 \%$ (Social Development in Fujian in 2002,). According to the survey of the aged population in China, $67.7 \%$ of elderly people feel economically guaranteed; $71.9 \%$ of them feel convenient to see doctors. And only $23.5 \%$ can get support from the local community when they need. $60.9 \%$ of them are satisfied with their present life (China Research Centre on Aging, 2003). Because of those complicated factors influencing suicide, China should pay more attention to the establishment of the public service system in order to supply financial and mental support for elderly people.

\section{7) Malignant neoplasms as a cause of death}

The mortality rate from malignant neoplasms was much higher in Japan than in Fujian. Stomach cancer was the leading cause of cancer deaths in both countries. The mortality rates from most malignant neoplasms such as lung, intestinal, leukemia, urinary bladder, breast and uterine cancer were higher in Japan than in Fujian. There were no clear differences in the mortality rates of stomach cancer or liver cancer between Fujian and Japan. Presently, stomach cancer, liver cancer, lung cancer, and esophageal cancer are the leading causes of cancer death in China (Dong $Z$, et al., 2002). The mortality rate from esophageal cancer in China was the highest among countries in the world in the 1970s'; however, it has gradually decreased since then ( $\mathrm{Li}$ $\mathrm{KE}, 2002$ ). In the present study, the mortality rate from esophageal cancer in Fujian was also remarkably high; it was 4 times higher than that in Japan among men, and 10.3 times higher than that in Japan among women.

The underlying causes of the decreasing tendency of the mortality rate from esophageal cancer in China are not clearly understood ( $\mathrm{Li} \mathrm{KE}$, 2002). It is thought that changes in dietary and environmental factors are two of the causes ( $\mathrm{Li}$ $\mathrm{KE}, 2002$ ). The diet and lifestyle of Japanese and Fujianese differ. Diet is estimated to be an important risk factor of human cancer. Many epidemiological studies have revealed that the relationship between dietary factors and cancers of the gastrointestinal tract including the stomach, colon-rectum and esophagus (Kneller RW et al., 1992; Blot WJ et al., 1993). The increased incidence of breast, ovarian and prostate cancers in Japan is also related to westernization of dietary habits (Kato I et al., 1987). A comparative study is required to elucidate the underlying factors contributing to the difference in the cancer mortality rates between Fujian Province and Japan. Further study focusing on the death notices data is deemed necessary in Fujian, China.

\section{Acknowledgments}

We would like to extend heartfelt appreciation to our many Chinese colleagues at Fujian Medical University for their cooperation. We would also like to express our gratitude to Professor Yutaka Inaba of Juntendo University for his warm advice and help. We also thank Professor Hiroshi Ueshima and Dr. Takehito Hayakawa of Shiga Prefecture University for their comments. Finally, the authors would like to thank Prof. Go TianKang of Chuo University for his personal support and kindly advice.

This study was sponsored by the Natural Scientific Foundation of Fujian Province (F0210003), and the Scientific Research Foundation for the Returned Overseas Chinese Scholars, State Edu- 
cation Ministry, P. R. of China.

\section{References}

Blot WJ, Li JY, Taylor PR, et al. (1993): Nutrition intervention trials in linxian, China: Supplementation with Specific Vitamin/mineral mortality in the general population. J Natl Cancer Inst, 85: 1483-1492

Chaoyang peng, Xiaodong Wu, Gordon Liu, et al (2002): Urban Air Quality and Health in China, Urban Studies, 39(12): 2283-2299

China Research Centre on Aging (2003): Data Analysis of the Sample of Survey of the Aged Population in China: 142-199 (in Chinese)

Chinese Academy of Preventive Medicine(1997) : Smoking in China : 1996 National Prevalance Survey of Smoking Pattern. Beijing : China Science and Technology Press

Dong X, Tang P, Li L, at al. (2002): The strategy for esophageal cancer control in High-risk area of China. Jpn J Clin Oncol, 32(Supple 1): S1012.

Editorial Committee of Fujian Yearbook (1998): Fujian Yearbook 1999. The People's Publication of Fujian: 31 (In Chinese)

Fu L, Hao J, He D, et al (2001): Assessment of Vehicular Pollution in China, Journal of the Air \& Waste Management Association, 51(5): 65868

$\mathrm{Gu}$ D (2003): The present condition and prospects of the vascular disease in China. Chinese Journal of Preventive Medicine, 37(2): 7576 (In chinese)

He J, Klag KK, Wu Z, et al. (1995): Stoke in the People's Republic of China _ Meta-Analysis of Hypertension and Risk of Stroke. Hypertension, 26(12): 2228-2232

Health and Welfare Statistics Association (1999): Journal of Health and Welfare Statistocs. : 46, 9.

Health and Welfare Statistics Association (2000): Journal of Health and Welfare Statistics. 47,9.

Health and Welfare Statistics Association (2001): Journal of Health and welfare statistics 2001., 48(9): 37, 190-191 (In Japanese)

Judith Mackay \& Michael Eriksen (2002): The Tobacco Atlas, Publications of World Health Organization: $95-97$

Junfeng Zhang, Wei Wu, Fusheng Wei, et al (2002): Children's Respiratory Morbidity
Prevalence in Relation to Air Pollution in Four Chinese Cities, Environmental Health Perspectives, 110(9): 961-67

Kato I, Tominaga S and Kuroishi T (1987): Relationship between Westernization of Dietary Habits and Mortality from Breast and Ovarian Cancers in Japan. Jpn. J. Cancer Res. (Gann), 78: 349-357

Kneller RW, Guo WD, Hsing AW, et al. (1992): Risk factors for stomach cancer in sixty-five Chinese counties. Cancer Epidemiology Biomark Prev, 1: 113-118

Lam TH, He Y, Li LS, et al. (1997): Mortality Attributable to Cigarette Smoking in China. JAMA, 278(18): 1505-1508

Li G, and Baker SP (1991): A Comparison of Injury Death Rates in China and the United States, 1986. American Journal of Public Health, 81(5): 605-609

Li KE (2002): Mortality and incidence trends from esophagus cancer in selected geographic areas of China circa 1970-90., 102: 271-274.

Liu Y, Rao K, Hsiao WC (2003): Medical expenditure and rural impoverishment in China. Journal of Health Popul Nutr, 21(3): 216-22

Maeda K, Nitta H (1996): Environmental Health, Journal of Epidemiology, 6(Supple 3): S121-4

Maedo K, Yasuda N, Ohara H, et al. (2000): Effects on Mortality of Getting the Basic Health Examination Under the Health Services for the Elderly Act and Modification of the Effects by Health Status Among Elderly Persons in a Rural Community. Journal of Epidemiology, 10 (1): $22-28$

Marilyn Beach (1999): China Millions Choke While Stoves Burn, the Lancet, 354(10): 137

Matsuo T (2003): Japanese Experiences of Environmental Management, Water Science and Technology, 47(1): 7-14

Ministry of Health People's Republic of China (1998): Research on National Health ServicesAn Analysis Report of the Second National Health Services Survey in 1998(I): 44 (In Chinese)

Ministry of Health People's Republic of China (1998): Chinese Health Statistical Digest: 26-30 (In Chinese)

Popkin BM, Keyou G, Zhai F, et al. (1993): The Nutrition Transition in China: a Cross-sectional Analysis. European Journal of Clinical Nutri- 
tion, 333-346

Shimokata H, Ando F, and Niino N (2000): A New Comprehensive Study on Aging-the national Institute for Longevity Sciences, Longitudinal Study of Aging (NILS-LSA). Journal of Epidemiology, 10(1): S-1

Sobue T (2001): Lung cancer, Gan to kagaku ryoho (Cancer \& chemotherapy), 28(2): 163-7

Social Development in Fujian in 2002. Fujian Daily, Feb. 28th (In Chinese)

Statistical Bureau of Fujian Province (2003): The Statistical Bulletin of National Economic and Social Development in Fujian in 2002. Fujian Daily, Feb. 28th, 2003 (In Chinese)

Statistics and information department, Minister's Secretariat, Ministry of Health and Welfare (1997): VITAL STATISTICS OF JAPAN 1997.

Statistics and information department, Minister's Secretariat, Ministry of Health and Welfare (2000): VITAL STATISTICS OF JAPAN 2000.

Statistics and Information Department Minister's Secretariat, Ministry of Health, Labour and Welfare (2001): Statistical Abstracts on Health and Welfare in Japan: 109
Tu F, Tokunaga S, Deng Z, et al. (2002): Analysis of hospital charges for cerebral infarction stroke inpatients in Beijing, People's Republic of China. Health Policy, 59(3): 243-56

Ueshima H (2001): "Kenkou Nippon 21" to Junkanki shikkan taisaku no tenkai (Progressing of "Health Japan 21" and circulatory organs disease measures.) Japanese Journal of Cardiovascular Disease Prevention, 36(2): 135139 (In Japanese)

Wang D, Zhou T, Deng L, et al. (2001): Study on the Prevalence and Disability of people 65 years and over in Fujian. Lit \& Inf Prev Med, 7(6): 626-627 (In Chinese)

Wang D, Deng L (2002): Study on the Prevalence of Chronic Diseases and the Affecting Factors for Aged People in A Senior School of Fuzhou. Strait J Prev Med, 8(5): 13-14 (In Chinese)

WHO (1995): Indoor Air Pollution database for China 1995.

Xu Z, Yu D, Jiang L, et al. (2000): Air pollution and daily mortality in Shenyang, China. Arch Environ Health Mar-Apr, 55(2): 115-20.

(Received 2. 12, 2004 ; Accepted 10. 1, 2004) 